\title{
Research Square \\ The development and validation of a Questionnaire in Bahasa Malaysia to assess problems of vision or feelings about vision among patients with cataracts.
}

Thanigasalam Thevi ( $D$ 111thevi@gmail.com )

Hospital Melaka https://orcid.org/0000-0002-9317-475X

Adinegara Lutfi Abas

Melaka Manipal Medical College

Stephanie Yen Li Chang

Melaka Hospital

Research article

Keywords: cataract, visual functioning questionnaire, factor analysis

Posted Date: September 11th, 2020

DOl: https://doi.org/10.21203/rs.3.rs-26080/v3

License: (c) (i) This work is licensed under a Creative Commons Attribution 4.0 International License.

Read Full License 


\section{Abstract}

Background We conducted the study to compare the validation properties of the English version of the Questionnaire and the Bahasa Malaysia (Malay Language) version regarding the Quality of Life of patients with cataracts.

Methods We carried out a cross-sectional study collecting data between June 2017 and March 2018 in the pre-operative Eye Clinic of Hospital Melaka.

The Malay version was translated by two independent translators who were well versed in both languages.

Methods used to validate the standard questionnaire included the use of construct validity via factor analysis and the deployment of reliability test through assessment of internal consistency via Cronbach's alpha.

Results We observed both English and Bahasa Malaysia versions to have high reliability with Cronbach's alpha values of 0.90 and above in factors on difficulty with activities and responses to vision problems.

Exploratory factor analysis performed revealed that the three-factor model fits the data well for the English version of the questionnaire - difficulty with activities ( $23.81 \%$ of variance), responses to vision problem (22.22\% of variance) and general health and vision ( $14.68 \%$ of variance).

The Bahasa Malaysia version of the questionnaire produced three factors with two of the factors resembling the factors from the original version of the questionnaire - difficulty with activities $(24.28 \%$ of variance) and responses to vision problem (23.66\% of variance).

Conclusion The present study observed that both the English and Bahasa Malaysia versions of the NEI VFQ-25 have comparable construct validity to the original American version. With high validity and reliability, the tool shall be able to provide health care providers the assessment of impact due to cataract and other ophthalmic conditions on the vision-related quality of life of ophthalmic patients.

\section{Background}

Cataract which is defined here as opacity of the lens has been noted as the leading cause of blindness contributing $39 \%$ of total blindness in Malaysia [1].The optimal treatment for cataract is cataract surgery. Challenges towards the implementation of surgical services in resource-limited environments are substantial and include limited human resources, transportation systems, and access to electricity and water [2].Cost-effectiveness plays a role in establishing and carrying out surgical services [3].

Monocular impairment and better-eye acuity were associated with a decrease in most domains representing quality of life [4]. A substantial increase in falls and fall injuries and poorer health related quality of life were found in the elderly with cataracts while waiting for surgery [5].A significant difference 
was observed between having cardiovascular diseases, respiratory and gastrointestinal diseases, hearing and visual impairments with poorer total score in the quality of life [6].

There have been various questionnaires developed to assess psychometric properties of illnesses that causes deterioration of vision. Patients with diseases such as diabetic retinopathy, cataract, primary open angle glaucoma, optic neuritis and uveitis have been included in research that evaluate vision related quality of life utilizing questionnaires that were deemed to be valid and reliable such as the VFQ-25 (questionnaire with 25 questions) and VFQ-51 (questionnaires with 51 questions) $[7,8,9]$.

The current paper was performed to report the processes involved in validating the National Eye Institute Visual Functioning Questionnaire - 25 (VFQ-25) which is primarily used to look into assessment of problems of vision and perception of quality of life among patients with cataracts.

\section{Materials And Methods}

We carried out a cross-sectional study collecting data between June 2017 and March 2018in the preoperative Eye Clinic of Hospital Melaka. Analysis was performed after data collection via the use of descriptive and inferential statistics. National Eye Institute Visual Functioning Questionnaire - 25 (VFQ25) version 2000 is an interviewer administered format available online which allows measurement of important health status of people with chronic eye diseases [7].

The original version of the VFQ-25 Questionnaire was in English but with majority of our population being able to converse and understand the Malay language which is our National language, we translated the English version into the Bahasa Malaysia version to cover population who are not literate in English.

The study was done to compare the validation properties of the English version of the Questionnaire and the Bahasa Malaysia (Malay Language) version regarding the Quality of Life of patients with cataracts. The study period included writing the proposal, collecting and analysing the data and completing the write-up. This VFQ-25 questionnaire was utilized to assess the quality of life in terms of problems of vision and feelings about vision among cataract patients in Melaka, Malaysia. The English version of the Questionnaire was obtained from National Eye Institute Visual Functioning Questionnaire - 25 (VFQ-25) version 2000.

We conducted the test on 400 plus participants who had cataract in the pre-operative Eye Clinic of Hospital Melaka. The English version of the Questionnaire was given to 200 plus patients and same number of Questionnaires in Malay Language was given to the other participants.

The Malay version was translated by two independent translators who were well versed in both languages. The patients were given consent form to sign to participate in the study. The Questionnaire was distributed by independent persons who were not part of the study. These data enumerators were trained on data collection methods. 
Methods used to validate the standard questionnaire included the use of construct validity via factor analysis and the deployment of reliability test through assessment of internal consistency via Cronbach's alpha. We regarded Cronbach's alpha values of 0.65 and above as fair and adequate for reliability testing.

The initial draft of the VFQ-25 contained 3 main parts and 8 subscales which included looking into the following domains - difficulty in performing activity in daily living, mental outlook/perception and personal satisfaction.

\section{Statistical Analysis}

We analyzed our data by using SPSS Version 25 . We began statistical analysis by examining our data using descriptive statistics which looks into the mean and standard deviation of each item in both English and Bahasa Malaysia versions of the questionnaire.

\section{Construct Validity}

For construct validity, we utilized factor analysis which is a statistical instrument used to condense and consolidate the items within the questionnaire into factors. These items are loaded into common factors with the main aim of consolidating the items into a small number of factors [10]. Loading here denotes the measure of association between an item and a factor.

We performed test to examine the adequacy of the sample and the suitability of data for factor analysis by examining the Kaiser-Meyer Olkin [11,12].

For data to be of value to our research, we utilized the following statistical cut-off values and ranges correlation coefficient values of 0.3 to 0.9 , $P$ value of correlation coefficient at less than 0.05 and Kayser Myer Olkin (KMO) sampling adequacy above 0.5 [13].

\section{Rotation}

We employed rotation to simplify and clarify the data structure. Rotation ensures maximum loading of each variable (item) into one extracted factor while at the same time ensuring that this same variable is not loaded into the other factors. We utilized orthogonal; methods such as Varimax, Quartimax and Equamax when variables were assumed to be orthogonal (independent of each other). For variables that were dependent of each other (oblique), we considered the use of Direct Oblimin and Promax. The usage of Equamax in our statistical study allowed us to produce factors that are uncorrelated.

\section{Ethical Consideration}

The approval to conduct this research was granted by the Medical Review and Ethics Committee (MREC) Ministry of Health Malaysia (06/02/2017). All participants gave written consent to participate in the study. 


\section{Results}

A total of 224 respondents took part in the analysis of the English version of the National Eye Institute Visual Functioning Questionnaire while another 204 participated in the Malay version.

The mean age of these patients was 66.8 years of age and 64.3 years of age for those involved in the English version and Bahasa Malaysia version respectively (Not In Table). The respondents were made up of $52.5 \%$ males in the English version and $49.8 \%$ males in the Bahasa Malaysia version. The main ethnic groups in the English version database comprised of Malays (56.1\%) followed by Chinese $(29.8 \%)$ and the Indians (14.1\%) while the Bahasa Malaysia version database consisted of Malays (53.7\%) followed by Chinese (31.2\%) and the Indians (15.1\%).

A total of 19 items each from the English version and Bahasa Malaysia version of the questionnaire were identified to be suitable for the component factor analysis.

As illustrated in Table 1, Kaiser-Meyer-Olkin's measure of sampling adequacy indicated excellent compactness with regards to the pattern of correlations with values of 0.923 for the English questionnaire and 0.927 for the Bahasa Malaysia questionnaire ( $P$ value $<0.05$ for Bartlett's Test). These results allowed us to proceed with factor analysis.

Table 1

Kaiser-Meyer-Olkin Measure of Sampling Adequacy of the English and Bahasa Malaysia Questionnaire in assessing problems and perceptions of vision, Hospital Melaka, 2018

Test English QuestionnaireBahasa Malaysia Questionnaire

Kaiser-Meyer-Olkin Measure of Sampling Adequacy0.923 0.927

Bartlett's Test of Sphericity

$\mathrm{P}<0.001 * * *$

$\mathrm{P}<0.001 * * *$

*** $\mathrm{P}$ value $<0.05$ Significant

We performed extraction of components followed by the use of all rotation types possible. Bearing in mind that items are independent of each other, we utilized Varimax rotation followed by Equamax rotation and finally ending with Quartimax rotation. We finally settled for the use of Equamax rotation as this rotation produces the least discrepancies in percentage of variance among the various components produced with Eigenvalue of more than one.

As shown in Table 2, a total of three components have eigenvalues of more than one with cumulative percentage of $60.7 \%$ for the English version of the questionnaire. Components one, two and three contributed $23.8 \%, 22.2 \%$ and $14.6 \%$ towards the total variance, respectively. As for the Bahasa Malaysia version of the questionnaire, similarly a total of three components presented with eigenvalues of one and above (Table 2 ). These three components accounted $24.2 \%, 23.6 \%$ and $18.6 \%$ respectively towards the 
total variance and together contributed a cumulative variance of $66.5 \%$ which was approximately $5.8 \%$ higher that the cumulative variance seen in the English version of the questionnaire.

Table 2

Total variance explained -Initial Eigenvalues and rotation sum via Equamax Rotation of the English and Bahasa Malaysia Questionnaire in assessing problems and perceptions of vision, Hospital Melaka, 2018

\begin{tabular}{|c|c|c|c|c|c|}
\hline \multirow{3}{*}{ Components } & \multicolumn{2}{|c|}{ Initial Eigenvalues } & \multicolumn{3}{|c|}{$\begin{array}{l}\text { Rotation sum of squared loadings (Equamax } \\
\text { Rotation) }\end{array}$} \\
\hline & Total\% of & Cumulative & Total & $\%$ of Variance & Cumulative \% \\
\hline & Variance & $\%$ & & & \\
\hline \multicolumn{6}{|c|}{ English Questionnaire } \\
\hline Component 1 & 8.4244 .34 & 44.34 & 4.52 & 23.81 & 23.81 \\
\hline Component 2 & 1.779 .35 & 53.70 & 4.22 & 22.22 & 46.04 \\
\hline Component 3 & 1.337 .01 & 60.72 & 2.79 & 14.68 & 60.72 \\
\hline \multicolumn{6}{|c|}{ Bahasa Malaysia } \\
\hline \multicolumn{6}{|l|}{ Questionnaire } \\
\hline Component 1 & 9.8251 .72 & 51.72 & 4.61 & 24.28 & 24.28 \\
\hline Component 2 & 1.829 .58 & 61.31 & 4.49 & 23.66 & 47.94 \\
\hline Component 3 & 1.005 .25 & 66.56 & 3.53 & 18.62 & 66.56 \\
\hline
\end{tabular}

In the English version of the questionnaire, nine items loaded strongly onto component one, six items were loaded onto component two and a further three items onto component three (Table 3). As for the Bahasa Malaysia version of the questionnaire, we observed loadings of 10 items, seven items and one item respectively onto components one, two and three respectively (Table 4). 
Table 3

The results of the final three factor solution of the English Questionnaire in assessing problems and perceptions of vision, via the use of Principal Component Analysis with Equamax rotation, Hospital Melaka, 2018

Items

Factor 1 Factor 2 Factor 3

LoadingsLoadingsLoadings

Difficulty with activities

B2Q5. How much difficulty do you have reading ordinary print in newspapers?

0.639

B2Q6. How much difficulty do you have doing work or hobbies that require you to see0.673

well up close, such as cooking, sewing, fixing things

B2Q8.How much difficulty do you have reading street signs or the names of stores? 0.699

B2Q9. Because of your eyesight, how much difficulty do you have going down steps, 0.674

stairs, or curbs in dim light or at night?

B2Q10. Because of your eyesight, how much difficulty do you have noticing objects $\quad 0.737$

off to the side while you are walking along?

B2Q11. Because of your eyesight, how much difficulty do you have seeing how $\quad 0.702$

people react to things you say?

B2Q12. Because of your eyesight, how much difficulty do you have picking out and $\quad 0.620$

matching your own clothes?

B2Q13. Because of your eyesight, how much difficulty do you have visiting with $\quad 0.673$

people in their homes, at parties, or in restaurants?

B2Q14. Because of your eyesight, how much difficulty do you have going out to see 0.597

movies, plays, or sports events?

Responses to vision problem

B3Q20. I stay home most of the time because of my eyesight.

0.714

B3Q21. I feel frustrated a lot of the time because of my eyesight.

0.695

B3Q22.I have much less control over what I do, because of my eyesight.

0.722

B3Q23. Because of my eyesight, I have to rely too much on what other people tell

0.778

me.

B3Q24. I need a lot of help from others because of my eyesight.

0.748

Page $7 / 16$ 
B3Q25. I worry about doing things that will embarrass myself or others, because of 0.760 my eyesight.

General health and vision

B1Q2.At the present time, would you say your eyesight using both eyes (with glasses

or contact lenses, if you wear them) is excellent, good, fair, poor, or very poor or are you completely blind?

B1Q3. How much of the time do you worry about your eyesight?

0.578

B2Q5. How much difficulty do you have reading ordinary print in newspapers?

0.422 
Table 4

The results of the final three factor solution of the Bahasa Malaysia Questionnaire (presented here in English) in assessing problems and perceptions of vision, via the use of Principal Component Analysis with Equamax rotation, Hospital Melaka, 2018

Items

Factor 1 Factor 2 Factor 3 LoadingsLoadingsLoadings

Difficulty with activities

B1Q2.At the present time, would you say your eyesight using both eyes (with glasses 0.678 or contact lenses, if you wear them) is excellent, good, fair, poor, or very poor or are you completely blind?

B2Q5. How much difficulty do you have reading ordinary print in newspapers? 0.786

B2Q6. How much difficulty do you have doing work or hobbies that require you to see 0.557 well up close, such as cooking, sewing, fixing things

B2Q8.How much difficulty do you have reading street signs or the names of stores? 0.766

B2Q9. Because of your eyesight, how much difficulty do you have going down steps, 0.718 stairs, or curbs in dim light or at night?

B2Q10. Because of your eyesight, how much difficulty do you have noticing objects $\quad 0.561$ off to the side while you are walking along?

B2Q11. Because of your eyesight, how much difficulty do you have seeing how 0.555 people react to things you say?

B2Q12. Because of your eyesight, how much difficulty do you have picking out and $\quad 0.479$ matching your own clothes?

B2Q13. Because of your eyesight, how much difficulty do you have visiting with $\quad 0.526$ people in their homes, at parties, or in restaurants?

B2Q14. Because of your eyesight, how much difficulty do you have going out to see 0.641 movies, plays, or sports events?

Responses to vision problem

B3Q20. I stay home most of the time because of my eyesight. 0.707

B3Q21. I feel frustrated a lot of the time because of my eyesight.

0.731 
B3Q22.I have much less control over what I do, because of my eyesight.

0.766

B3Q23. Because of my eyesight, I have to rely too much on what other people tell

0.833

me.

B3Q24. I need a lot of help from others because of my eyesight.

0.751

B3Q25. I worry about doing things that will embarrass myself or others, because of

0.793 my eyesight.

B3Q18 Are you limited in how long you can work or do.

0.490

Less accomplishment due to poor eyesight

B3Q17.Do you accomplish less than you would like because of your vision?

$-0.777$

The loading process in component one (defined here as "Difficulty in Activity of Daily Living") revealed nine similar items for both English and Bahasa Malaysia versions of the questionnaire (Table 3 and Table $4)$.

As for component two (defined here as "Dependency on others due to poor eyesight"), the loading revealed six similar items for both English and Bahasa Malaysia versions of the questionnaire (Table 3 and Table 4).

The English version of the National Eye Institute Visual Functioning Questionnaire comprises of three components:

1) Component one: "Difficulty with activities", which accounted for $23.8 \%$ of the total variance. This component contained nine items and reflected perception of the difficulty in activity of daily living. The highest loading items were as follows - "Because of your eyesight, how much difficulty do you have noticing objects off to the side while you are walking along?" (factor loading of 0.73 ); "Because of your eyesight, how much difficulty do you have seeing how people react to things you say?" (factor loading of 0.84 ); "How much difficulty do you have reading street signs or the names of stores?" (factor loading of $0.69)$.

2) Component two: "Responses to vision problems", which comprised of $22.2 \%$ of the total variance. Six items were included within this component which reflected perception on dependency on others due to poor eyesight. We noted the highest loading items as follows - "Because of my eyesight, I have to rely too much on what other people tell me." (factor loading of 0.77 ); "I worry about doing things that will 
embarrass myself or others, because of my eyesight." (factor loading of 0.76 ); "I need a lot of help from others because of my eyesight." (factor loading of 0.74 ).

3) Component three: "General health and vision", which contributed $14.6 \%$ of the total variance. This component comprised of three items which portrayed poor perception of respondents on status of eyesight. The following items were loaded highest as follows -

"At the present time, would you say your eyesight using both eyes (with glasses or contact lenses, if you wear them) is excellent, good, fair, poor, or very poor or are you completely blind?" (factor loading of 0.60 ); "How much of the time do you worry about your eyesight?" (factor loading of 0.57); "How much difficulty do you have reading ordinary print in newspapers?" (factor loading of 0.42 ).

The final Bahasa Malaysia version of the National Eye Institute Visual Functioning Questionnaire constitutes the following three components:

1) Component one: "Difficulty with activities", contributing towards $23.6 \%$ of the total variance. A total of ten items were loaded which reflected perception of the difficulty in activity of daily living. The highest loading items were as follows - "How much difficulty do you have reading ordinary print in newspapers?" (factor loading of 0.78 ); "How much difficulty do you have reading street signs or the names of stores?" (factor loading of 0.76 ); "Because of your eyesight, how much difficulty do you have going down steps, stairs, or curbs in dim light or at night?" (factor loading of 0.71 ).

2) Component two: "Responses to vision problems", comprising of $24.2 \%$ of the total variance. We observed seven items that were included within this component which reflected perception on dependency on others due to poor eyesight. The highest loading items were as follows -

"Because of my eyesight, I have to rely too much on what other people tell me." (factor loading of 0.83 ); "I have much less control over what I do, because of my eyesight." (factor loading of 0.76 ); "I feel frustrated a lot of the time because of my eyesight." (factor loading of 0.73 ).

3) Component three: "Poor perception of status of eyesight", accounting for $18.6 \%$ of the total variance. There was only one item loaded into the component which portrayed poor perception of respondents on status of eyesight. The lone item loaded was noted as follows -

"Do you accomplish less than you would like because of your vision?" (factor loading of -0.77).

\section{Reliability - Internal Consistency}

After construct validation was computed, Cronbach's alpha was computed for the revised questionnaire and we obtained Cronbach alpha values of $0.904,0.898$ and 0.608 for the three components of the English version of the questionnaire - difficulty with activities, responses to vision problems and general health and vision. As for the Bahasa Malaysia version, computation of Cronbach's alpha revealed values of $0.921,0.927$ for the first two components - difficulty with activities, responses to vision problems. 
Cronbach's alpha was not done on Component 3 (general health and vision) of the Bahasa Malaysia version as Component 3 has only one item.

\section{Discussion}

The National Eye Institute Visual Functioning Questionnaire - 25 (NEI VFQ 25) has been designed to measure important areas of well-being and functioning among patients with eye diseases [14]. It has been further described as a valid and reliable tool in assessing vision-specific quality of life among patients with various eye diseases [15].

The ultimate aim of this study was to translate the National Eye Institute Visual Functioning Questionnaire-25 into Bahasa Malaysia and validate both versions (English and Bahasa Malaysia) on their capacity in measuring and assessing quality of life of people with cataracts. We assessed the reliability and validity of the English and Bahasa Malaysia version of the NEI VFQ-25 in ophthalmic patients with cataract diseases.

The original National Eye Institute Visual Functioning Questionnaire - 25 which was first developed by RAND [16] is comprised of three factors which touched upon general health and vision, difficulty with activities and responses to vision problem.

We observed both English and Bahasa Malaysia versions to have high reliability with Cronbach's alpha values of 0.90 and above in factors on difficulty with activities and responses to vision problems which mirrored results seen in studies validating the questionnaire in Japanese [17], Italian [18], French [19], Spanish [20], Turkish [21] and German [22].

With regards to construct validity, exploratory factor analysis performed has revealed that the three-factor model fits the data well for the English version of the questionnaire. Extraction and rotation of the data produced a model that mirrored the original version with regards to production of a total of three factors - difficulty with activities (23.81\% of variance), responses to vision problem (22.22\% of variance) and general health and vision ( $14.68 \%$ of variance). The items were mostly similar between the model and the original questionnaire in these three factors- there were a total of nine identical items shared in the factor on difficulty with activities, six identical items shared in the factor on responses to vision problem and two similar items shared in the factor on general health and vision. The results supported a three-factor solution as per original version of the questionnaire, with the factors accounting for $60.72 \%$ of the variance.

However, there were a couple of items left out in the model. For instance, on difficulty with activities, two items which pertain to driving at night and driving in difficult conditions were omitted from the model. Similarly, a study by Lloyd et al noted that driving in difficult conditions or at night items merged out into a totally separate domain [23]. 
A further three items on accomplishment, limitation of work activities and pain discomfort were left out from the model in the factor on responses to vision problems.

As similarly seen in the English version, the Bahasa Malaysia version of the questionnaire produced three factors with two of the factors resembling the factors from the original version of the questionnaire difficulty with activities ( $24.28 \%$ of variance) and responses to vision problem ( $23.66 \%$ of variance). In addition, there was higher cumulative variance in the Bahasa Malaysia version (66.56\% Bahasa Malaysia version versus $60.72 \%$ English version) indicating stronger fit to the model for the Bahasa Malaysia version as compared to the English version. Altogether, there were a total of ten identical items shared in the factor on difficulty with activities and seven identical items shared in the factor on responses to vision problem between the Bahasa Malaysia and the original version of the questionnaire.

Factor analysis on the Brazilian version of the NEI VFQ-25 indicated that the tool could be utilized in the country to assess vision-related quality of life as the psychometrics properties are comparable to the original American version [24]. The Japanese version of the questionnaire also noted similar observation [17].

However, in comparison to these studies conducted in Brazil [24] and Japan [17] which focused on subscales derived from the optional questions rather than the main parts of the questionnaire, our research revealed three factor model - difficulty with activities, responses to vision problem and general health and vision which mirrored precisely with the main parts of the original NEI VFQ-25 questionnaire (Part 2, Part 3 and Part 1 respectively). In addition, as the population of Malaysia are well conversant in both the Malay and English languages, we were able to perform validation analyses for questionnaires in both languages and ultimately witness the high reliability and validity in these questionnaires in assessing the quality of life of people with cataract.

With good reliability and validity, the VFQ-25 has been utilized in surveys involving ophthalmic patients with diabetic retinopathy, primary open-angle glaucoma, cataract, low vision, optic neuritis, uveitis and others such as age-related macular degeneration and cytomegalovirus retinitis $[9,25,26,27,28]$.

This study with good psychometric features could be used as a routine tool to assess visual function among patients especially among rural folks who predominantly understand Bahasa Malaysia which is the official language in Malaysia. In addition, this study validates the use of the English version of the questionnaire which may be utilized by those who prefer the use of the English language which is especially seen among the urban population of Malaysia.

\section{Conclusion}

The present study observed that both the English and Bahasa Malaysia versions of the NEI VFQ-25 have comparable construct validity to the original American version. With high validity and reliability, the tool shall be able to provide health care providers the assessment of impact due to cataract and other ophthalmic conditions on the vision-related quality of life of ophthalmic patients. 


\section{Abbreviations}

NEI VFQ- National Eye Institute Visual Functioning Questionnaire

MREC-Medical Research Ethics Committee

\section{Declarations}

Ethics approval and consent to participate-Medical Research and Ethics committee Malaysia (MREC)$\mathrm{NIH}$.

Consent for publication-Director General of Health Malaysia

Availability of data and materials-hard copies can be provided.

Competing interests-Nil

Funding-Nil

Authors' contributions- TT contributed to the conception and design of study. TT and CYLS participated in providing the material tools. TT involved in acquisition of data. ALA performed the data analysis and drafted the manuscript. All authors read, commented and approved the final manuscript.

Acknowledgements- The authors wish to thank the Director-General of Health, Ministry of Health Malaysia for the support to publish the study. We would also like to thank the Hospital Director Dr Hatijah Mohd Tan and Head of Ophthalmology Dept Dr Raja Norliza for granting permission to conduct this study. We also thank all the participants for their effort in cooperating in this study.

Authors' information-1. TT-Ophthalmologist Hospital Melaka. 2.ALA-Dean and HOD Community Medicine Melaka Manipal Medical College. 3.CYLS-Student Melaka Manipal Medical College and House officer Hospital Melaka.

\section{References}

1. Zainal M, Ismail SM, Ropilah AR, Elias H, Arumugam G, Alias D, Fathilah J, Lim TO, Ding LM, Goh PP. Prevalence of blindness and low vision in Malaysian population: results from the National Eye Survey1996. Br J Ophthalmol. 2002;86(9):951-6.

2. Hsia RY1, Mbembati NA, Macfarlane S, Kruk ME. Acess to emergency and surgical care in subSaharan Africa: the infrastructure gap. Health Policy Plan. 2012;27(3):234-44.

3. Loo CY, Kandiah M, Arumugam G, Goh PP, John E, Gurusami B, Kumar TV, Karunakar TV, Azmi S, Lim TO. Cost efficiency and cost effectiveness of cataract surgery at the Malaysian Ministry of Health ophthalmic services. Int Ophthalmol. 2004;25(2):81-7. 
4. Broman AT, Munoz B, Rodriguez J, Sanchez R, Quigley HA, Klein R, Snyder R, West SK. The impact of visual impairment and eye disease on vision-related quality of life in a Mexican-American population: proyecto VER. Invest Ophthalmol Vis Sci. 2002;43(11):3393-8.

5. Palagyi A, McCluskey P, White A, Rogers K, Meuleners L, Ng JQ, Morlet N, Keay L. While We Waited: Incidence and Predictors of Falls in Older Adults With Cataract. Invest Ophthalmol Vis Sci. 2016;57(14):6003-6010.

6. Khaje-Bishak Y, Payahoo L, Pourghasem B, Asghari Jafarabadi M. Assessing the Quality of Life in Elderly People and Related Factors in Tabriz, Iran. J Caring Sci. 2014; 3(4): 257-263.

7. Mangione CM, Lee PP, Gutierrez PR, Spritzer K, Berry S, Hays RD. Development of the 25-item National Eye Institute Visual Function Questionnaire. Arch Ophthalmol. 2001;119(7):1050-8.

8. Mangione CM, Lee PP, Pitts J, Gutierrez PR, Berry S, Hays RD. Psychometric properties of the National Eye Institute Visual Function Questionnaire (NEI-VFQ). Arch Ophthalmol. 1998;116(11):1496-504.

9. Cole SR, Beck RW, Moke PS, Gal RL, Long DT. The National Eye Institute Visual Function Questionnaire: experience of the ONTT. Invest Ophthalmol Vis Sci. 2000;41:1017-1021.

10. Bryman A, Cramer D. Quantitative Data Analysis with SPSS Release 8 for Windows. A Guide for Social Scientists. London: Routledge, 1999.

11. Burton LJ, Mazerolle SM. Survey Instrument Validity Part I: Principles of Survey Instrument Development and Validation in Athletic Training Education Research." Athletic Training Education Journal. 2011;6(1): 27-35.

12. KaiserHF. A Second-Generation Little Jiffy.Psychometrika. 1970;35(4): 401-415.

13. Kaiser H. An index of factorial simplicity Psychometrika. 1974;39(1):31-36.

14. Clemons TE, Chew EY, Bressler SB, McBee W. National Eye Institute Visual Function Questionnaire in the Age-Related Eye Disease Study (AREDS). Arch Ophthalmol. 2003;121:211-217.

15. Cusick M, San Giovanni JP, Chew EY, Csaky KG, Hall-Shimel K, Reed GF, et al. Central visual function and the NEI-VFQ-25 near and distance activities subscale scores in people with type 1 and 2 diabetes. Am J Ophthalmol. 2005;139(6):1042-50.

16. RAND Health Care. Visual Function Questionnaire (VFQ-25). https://www.rand.org/healthcare/surveys_tools/vfq.html (accessed 22nd May 2019).

17. Suzukamo Y, Oshika T, Yuzawa M, Tokuda Y, Tomidokoro A, Oki K, et al. Psychometric properties of the 25-Item National Eye Institute Visual Function Questionnaire (NEI VFQ-25), Japanese version. Health Qual Life Outcomes. 2005;3:65.

18. Rossi GC, Milano G, Tinelli C. The Italian version of the 25-Item National Eye Institute Visual Function Questionnaire: translation, validity, and reliability. J Glaucoma. 2003;12(3):213-20.

19. Nordmann JP, Viala M, Sullivan K, Arnould B, Berdeaux G. Psychometric Validation of the National Eye Institute Visual Function Questionnaire - 25 (NEI VFQ-25) French version: in a population of patients treated for ocular hypertension and glaucoma. Pharmacoeconomics. 2004;22(3):197-206. 
20. Broman AT, Munoz B, West SK, Rodriguez J, Sanchez R, Snyder R, Klein R. Psychometric properties of the 25-Item NEI-VFQ in a Hispanic population: Proyecto VER. Invest Ophthalmol Vis Sci. 2001;42(3):606-13.

21. Toprak AB, Eser E, Guler C, Baser FE, Mayali H. Cross-validation of the Turkish version of the 25-Item National Eye Institute Visual Functioning Questionnaire (NEI-VFQ 25). Ophthalmic Epidemiol. 2005;12(4):259-69.

22. Franke GH, Esser J, Reimer J, Maehner N. Vision targeted quality of life under different degrees of vision impairment. Rev Port Psicossom. 2002;4(1):39-49.

23. Lloyd AJ, Loftus J, Turner M, Lai G, Pleil A. Psychometric validation of the visual function questionnaire-25 in patients with diabetic macular edema. Health and Quality of Life Outcomes. 2013;11:1-11.

24. Simão LM, Lana-Peixoto MA, Araújo CR, Moreira MA, Teixeira AL. The Brazilian version of the 25-Item National Eye Institute Visual Function Questionnaire: translation, reliability and validity. Arq Bras Oftalmol. 2008;71(4):540-6.

25. Mangione CM, Lee PP, Pitts J, Gutierrez P, Berry S, Hays RD. Psychometric properties of the National Eye Institute Visual Function Questionnaire (NEI-VFQ). Arch Ophthalmol. 1998;116:1496- 1504

26. Mangione CM, Lee PP, Pitts J, Gutierrez P, Berry S, Hays RD. Development of the 25-item National Eye Institute Visual Function Questionnaire. Arch Ophthalmol. 2001;119:1050-1058

27. Parrish RK II, Gedde SJ, Scott IU, et al. Visual function and quality of life among patients with glaucoma. Arch Ophthalmol. 1997;115:1447-1455

28. Scott IU, Smiddy WE, Schiffman J, Feuer WJ, Pappas CJ. Quality of life of low-vision patients and the impact of low-vision services. Am J Ophthalmol. 1999;128:54-62. 